\title{
Microstructural Evolution during Isothermal Aging in Ni-Rich Ti-Zr-Ni Shape Memory Alloys
}

\author{
Adrian Mihai Sandu ${ }^{1, *}$, Koichi Tsuchiya ${ }^{1}$, Masayuki Tabuchi ${ }^{2}$, Shinya Yamamoto $^{1}$, \\ Yoshikazu Todaka ${ }^{1}$ and Minoru Umemoto ${ }^{1}$ \\ ${ }^{1}$ Dept. of Production Systems Engineering, Toyohashi University of Technology, Toyohashi 441-8580, Japan \\ ${ }^{2}$ Hakodate Polytechnic College, Hakodate 042-8501, Japan
}

\begin{abstract}
Microstructural evolution during isothermal aging at temperatures ranging from $673 \mathrm{~K}$ to $773 \mathrm{~K}$ was investigated by transmission electron microscopy (TEM) for Ni-rich Ti-Zr-Ni alloys. It was revealed that the aging is a two-stage process: the first stage is characterized by circular diffuse scattering in electron diffraction patterns, most likely attributed to short range ordered structure with no significant microstructural change. Second stage is characterized by a fine coherent precipitation followed by the coarsening. The precipitates had a lenticular shape and their habit was $\{100\}_{\mathrm{B} 2}$. The electron diffraction pattern of the sample containing the precipitates exhibited satellite spots at $1 / 3\langle 110\rangle_{\mathrm{B} 2}$ and $1 / 4\langle 210\rangle_{\mathrm{B} 2}$ positions. High resolution TEM observations and fast Fourier transformation analysis revealed that the $\langle 100\rangle_{\mathrm{B} 2}$ electron diffraction pattern was composed of the reflection from 4 variants of the precipitates. The two-stage microstructural evolutions coincide well with the previously reported changes in mechanical properties and martensitic transformation behavior. [doi:10.2320/matertrans.48.432]
\end{abstract}

(Received September 21, 2006; Accepted December 7, 2006; Published February 25, 2007)

Keywords: shape memory alloys, martensitic transformation, aging, precipitation, short range ordering

\section{Introduction}

Superelasticity (SE), shape memory effect (SME) and biocompatibility of TiNi based shape memory alloys have found various applications in medical devices, such as guidewires and stents, as well as actuators for various appliances. The SE and SME are closely related to martensitic or R-phase transformation. Thus, the control of transformation temperatures and mechanical properties becomes very important for practical applications. The properties of TiNi can be modified by adequate thermomechanical treatment and by changing alloy composition. In the case of Ni-rich TiNi, aging at temperatures between $673 \sim 773 \mathrm{~K}$ results in the fine precipitation of $\mathrm{Ti}_{3} \mathrm{Ni}_{4}$ phase, which significantly strengthens the material and thus leads to improved SME and SE properties. ${ }^{1)}$ Addition of the third element is also common method to modify the properties. Addition of noble metal elements, such as, Au, Pt and Pd, or rare earth elements, such as, Hf increases martensitic transformation temperature ${ }^{2)}$ while the addition of the most of transition metal elements decreases the transformation temperatures with $\mathrm{Zr}$ being an exception. Also $\mathrm{Zr}$ addition may lead to an improvement of biocompatibility because of its high affinity with oxygen and ability to form stable oxides. A number of investigations subjecting $\mathrm{Ti}-\mathrm{Zr}-\mathrm{Ni}$ shape memory alloys have been carried out. ${ }^{3-9)}$ However, limited information is available regarding the effect of aging on phase transformation and mechanical properties in $\mathrm{Ti}-\mathrm{Zr}-\mathrm{Ni}$ alloys, and if the precipitation behaviour similar to the one observed in a Ni-rich binary TiNi occurs during aging.

In our previous research it was revealed that the transformation temperatures decrease in the early stage of aging and then turn to increase in the latter stage. ${ }^{10)}$ On the other hand, the hardness increased in the initial stage followed by a slight decrease after the longer aging. The aging conditions which give the highest hardness correspond roughly to the

*Graduate Student, Toyohashi University of Technology one that gives the lowest martensitic transformation temperature. Similar tendency can be seen for other aging temperatures. It can be thus inferred that these two aging effects are mutually related and may have their origins in common. It was also revealed that the initial aging stage is accompanied by no significant change in microstructure, except for intensifying the diffuse scattering in electron diffraction patterns while the later aging stage was accompanied by fine precipitation.

The present report presents the details in microstructure during aging, such as, the morphology and structure of the precipitates as well as their effect on compression deformation.

\section{Experimental Procedures}

Ingots of Ti-6.0 mol\%Zr-52 mol\% Ni, Ti-6.0 mol\%Zr-53 mol\% $\mathrm{Ni}$ and $\mathrm{Ti}-11.1 \mathrm{~mol} \% \mathrm{Zr}-51.5 \mathrm{~mol} \% \mathrm{Ni}$ were prepared using a tri-arc melting furnace. They were homogenized in evacuated quartz tube for $605 \mathrm{ks}$ ( 7 days) at $1073 \mathrm{~K}$ under an argon atmosphere followed by water quenching. The alloys were isothermally aged for various time durations up to $360 \mathrm{ks}$ at temperatures from 673 to $773 \mathrm{~K}$ in an argon gas atmosphere. Cylindrical samples for compression test having a height of $3.9 \mathrm{~mm}$ and a diameter of $2.2 \mathrm{~mm}$ were cut from Ti-6.0 mol\%Zr-53 mol\% Ni ingot. Compression tests were performed on Shimadzu AGS-J apparatus imposing an $8 \%$ deformation for 5 consecutive cycles at room temperature. During the compression deformation the both ends of the samples were lubricated with $\mathrm{BN}$ powder to minimize the effect of friction. Strain was measured by video extensometer. After each compression cycle the sample was heated over austenitic transformation finish temperature. TEM samples were carefully cut from the ingots and from ascompressed samples as well. Specimens were electrochemically polished using an electrolyte of $20 \% \mathrm{H}_{2} \mathrm{SO}_{4}$ and $80 \%$ methanol at $253 \mathrm{~K}$. Microstructural observations were done using Hitachi H-800 and JEOL JEM-2010 transmission electron microscopes (TEM) both operated at $200 \mathrm{kV}$. 


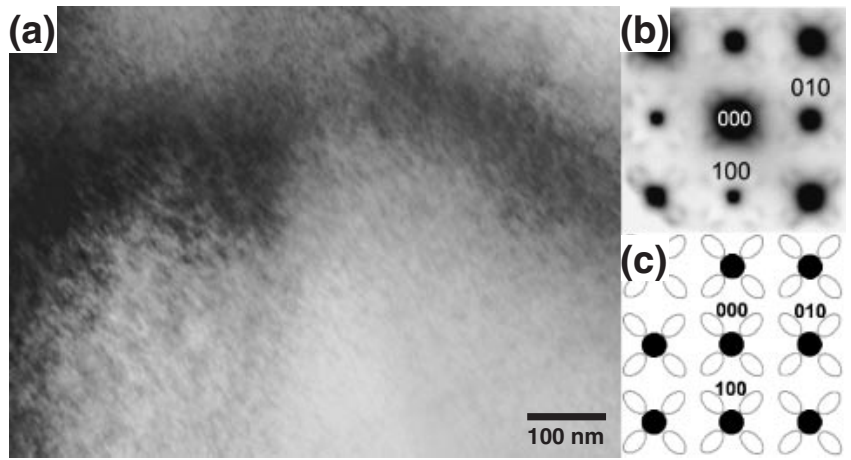

Fig. 1 Microstructure of Ti-6Zr-52Ni aged for $3.6 \mathrm{ks}$ at $773 \mathrm{~K}$ : (a) Bright field image of $\mathrm{B} 2$ phase; (b) selected area diffraction pattern $\left(\mathrm{e}^{-} / /\right.$ $\left.[001]_{\mathrm{B} 2}\right)$; (c) key diagram.

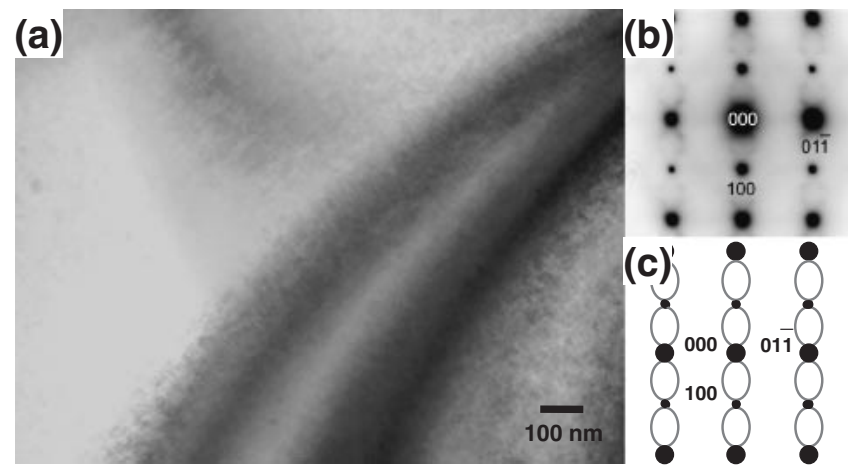

Fig. 2 Microstructure of Ti-6Zr-52Ni aged for $3.6 \mathrm{ks}$ at $773 \mathrm{~K}$ : (a) Bright field image of $\mathrm{B} 2$ phase; (b) selected area diffraction pattern, $\left(\mathrm{e}^{-} / /\right.$ $\left.[011]_{\mathrm{B} 2}\right)$; (c) key diagram.

\section{Results and Discussion}

\subsection{Changes in microstructures by aging in Ti-6.0 mol\%Zr-52 mol\% Ni}

Figure 1 shows a bright field (BF) image (a), selected area diffraction (SAD) pattern with the electron beam parallel to $[001]_{\mathrm{B} 2}$ (b) and its key diagram (c) for Ti-6.0 mol\%Zr-52 mol\% $\mathrm{Ni}$ aged at $773 \mathrm{~K}$ for $3.6 \mathrm{ks}$. The SAD pattern exhibits circular diffuse scattering around the main spots of the B2 phase. They are slightly elongated in the directions parallel to $\langle 110\rangle_{\mathrm{B} 2}$ and exhibit the four-fold symmetry around the main spots. The diffuse scattering is different from those due to the precursor effect of R-phase often observed in binary $\mathrm{TiNi},{ }^{11)}$ and thus is most likely related to the short range ordered arrangement of $\mathrm{Zr}$ atoms. These features were essentially identical with the ones noted for the as-homogenized sample. TEM image from a different region of this sample is shown in Fig. 2. The BF image (Fig. 2(a)) exhibits only the bend contour and no second phase is seen. However, circular diffuse scattering are noted in the corresponding SAD pattern with the electron beam parallel to $[011]_{\mathrm{B} 2}$ presented in Fig. 2(b). They are elongated in the directions parallel to $\langle 100\rangle_{\mathrm{B} 2}$ as depicted in the key diagram (Fig. 2(c)).

Figure 3 shows a BF image (a), the corresponding SAD pattern (b) and its key diagram (c) of the sample aged at $773 \mathrm{~K}$ for $14.4 \mathrm{ks}$. Numerous flat precipitates with $(100)_{\mathrm{B} 2}$ or $(010)_{\mathrm{B} 2}$ habit are seen in the BF image (Fig. 3(a)). The precipitates are surrounded by dark contrasts associated with

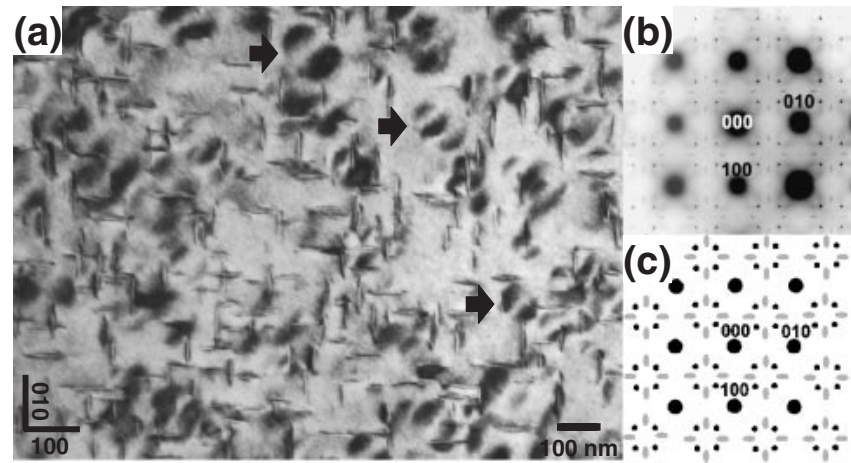

Fig. 3 Microstructure of Ti-6Zr-52Ni aged for $14.4 \mathrm{ks}$ at $773 \mathrm{~K}$ : (a) Bright field image of plate-like precipitates; (b) selected area diffraction pattern, $\left(\mathrm{e}^{-} / /[001]_{\mathrm{B} 2}\right) ;(\mathrm{c})$ key diagram.

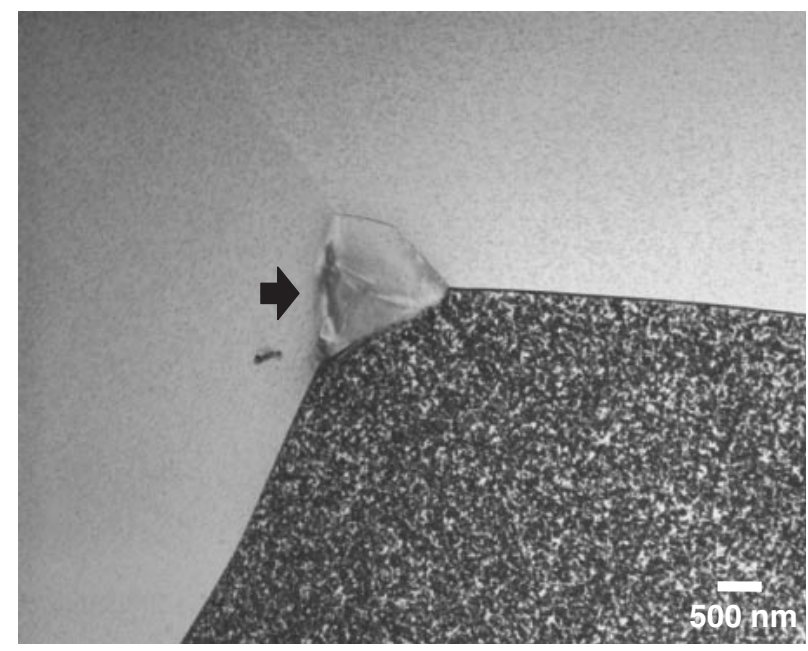

Fig. 4 Bright field image of Ti-6Zr-52Ni aged for $14.4 \mathrm{ks}$ at $773 \mathrm{~K}$.

elastic strain fields. Also in the BF image, dark lobes with a line of no contrast in the middle can be seen as indicated by the arrows. They are a typical of precipitates with a circular perimeter accompanied by coherency strain around them. Thus, it is inferred that the precipitates are lenticular with their habit on $\{100\}_{\mathrm{B} 2}$. The size of the precipitates is about $70 \mathrm{~nm}$ in diameter and about $20 \mathrm{~nm}$ thick. The SAD (Fig. 3(b)) indicates sharp satellite spots at $1 / 3\langle 110\rangle_{\mathrm{B} 2}$ and diffuse satellite at $1 / 4\langle 210\rangle_{\mathrm{B} 2}$ elongated in $\langle 100\rangle_{\mathrm{B} 2}$ directions. The SAD pattern is clearly different from that of the aged TiNi with $\mathrm{Ti}_{3} \mathrm{Ni}_{4}$ precipitates, which exhibits satellite spots at $1 / 7\langle 321\rangle_{\mathrm{B} 2}$, and from that of the sputtered Ti-rich Ti$48.2 \mathrm{~mol} \% \mathrm{Ni}$ thin films aged at $745 \mathrm{~K}$ for $3.6 \mathrm{ks} .{ }^{12,13)}$ Careful examination of the films revealed that the diffuse scattering rings are still present in SAD pattern shown in Fig. 3(b).

Figure 4 shows a distribution of the precipitates. These precipitates are uniformly distributed throughout the B2 grains and the region near the grain boundaries. This feature is also maintained near the Laves phase $(\mathrm{Ti}, \mathrm{Zr})_{2} \mathrm{Ni}$ (marked by black arrow), which is occasionally found at the grain boundaries.

Figure 5 is a closer look of the area shown in Fig. 4 with corresponding SAD pattern $\left(\mathrm{e}^{-} / /[111]_{\mathrm{B} 2}\right)$ as an inset for the sample aged at $773 \mathrm{~K}$ for $14.4 \mathrm{ks}$. The SAD pattern reveals additional spots situated at $1 / 3\langle\overline{1} 10\rangle_{\mathrm{B} 2}$ direction. Also, the 
closer examination of the image revealed $\langle 110\rangle_{\mathrm{B} 2}$ diffuse streaks connecting the $\mathrm{B} 2$ fundamental reflections.

Figure 6(a) shows a high resolution image of a sample aged at $773 \mathrm{~K}$ for $144 \mathrm{ks}$. Fig. 6(b) is a key diagram of SAD pattern. The B2 main spots are indicated by large black circles; satellite spots are indicated by small black solid and open circles, and dark and light gray ellipses. The insets

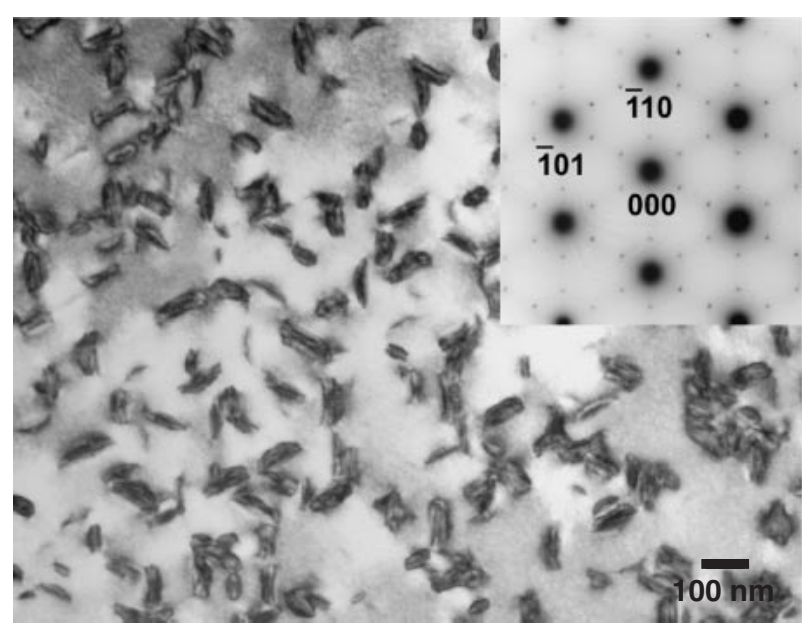

Fig. 5 Bright field image of Ti-6Zr-52Ni aged for $14.4 \mathrm{ks}$ at $773 \mathrm{~K}$. Inset is the electron diffraction pattern, $\left(\mathrm{e}^{-} / /[111]_{\mathrm{B} 2}\right)$. denoted as $\mathrm{A}, \mathrm{B}$ and $\mathrm{C}$ are the fast Fourier transformation (FFT) images obtained from the areas marked as A, B and C in Fig. 6(a), respectively. Area A contains only the B2 matrix. Areas $\mathrm{B}$ and $\mathrm{C}$ contain a precipitate with its habit in the foil plane and perpendicular to the foil plane, respectively. Approximate perimeters of the precipitates are outlined by dotted lines in the figure. The FFT image for the area A exhibits the B2 reflections only. In the inset B, along B2 main spots, one can note the presence of a series of satellite reflections positioned at $1 / 3\langle 110\rangle_{\mathrm{B} 2}$, corresponding to the black small solid circles in the key diagram (Fig. 6(b)). No other satellite reflections can be noted in the FFT image, thus the satellites shown as the full small black circles in Fig. 6(b) come from the in-plane precipitates. In the inset $\mathrm{C}$ a series of satellites situated at $1 / 4\langle 210\rangle_{\mathrm{B} 2}$ is seen; they correspond to the ones indicated as a dark gray ellipses in Fig. 6(b). No other spots are observed in inset $\mathrm{C}$ from Fig. 6. Thus, it is inferred that the reflections originate from the precipitate with its habit normal parallel to $\langle 010\rangle_{\mathrm{B} 2}$. It should be also noted that the satellites are elongated in the directions perpendicular to the habit of the precipitates. The length of elongated spots corresponds well to the thickness of the precipitates $(\sim 20 \mathrm{~nm})$. Hence the observed SAD as shown in Fig. 3(b) can be interpreted as the electron diffraction from 4 variants of the precipitates. The appearance of satellite reflections indicates that the crystal structure of the precip-

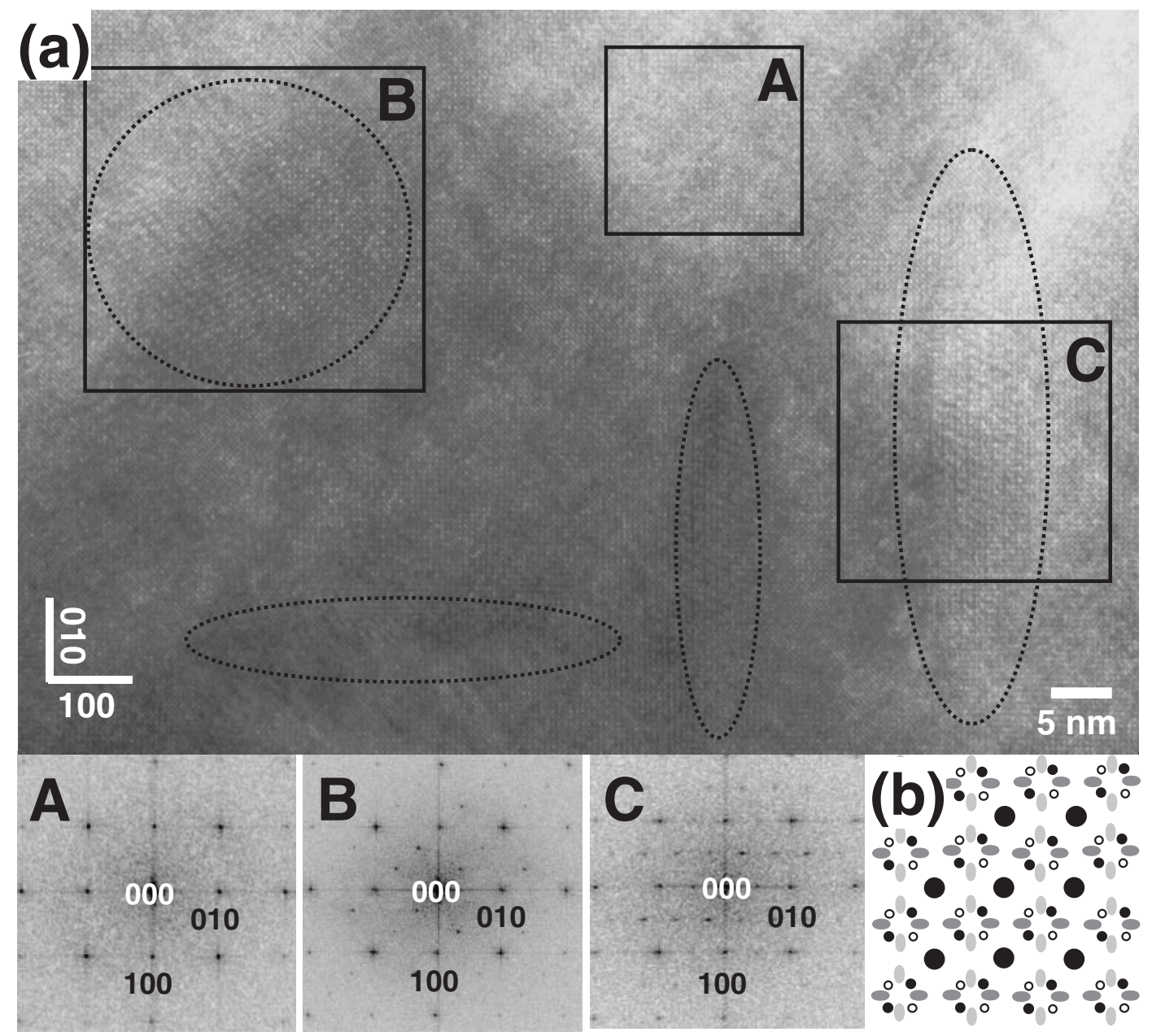

Fig. 6 Microstructure of Ti-6Zr-52Ni aged for $144 \mathrm{ks}$ at $773 \mathrm{~K}$ : (a) high resolution TEM image; insets A, B and C shows the fast Fourier transformation (FFT) images obtained from the area A, B and C in (a); (b) key diagram for FFT images. 


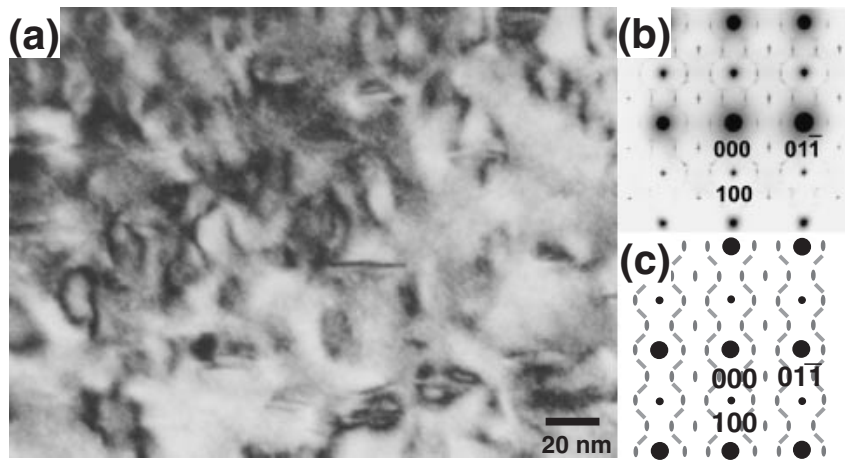

Fig. 7 Microstructure of Ti-6Zr-52Ni aged for $144 \mathrm{ks}$ at $773 \mathrm{~K}$ : (a) Bright field image of B2 phase and precipitates; (b) selected area diffraction pattern, $\left(\mathrm{e}^{-} / /[011]_{\mathrm{B} 2}\right)$; (c) key diagram.

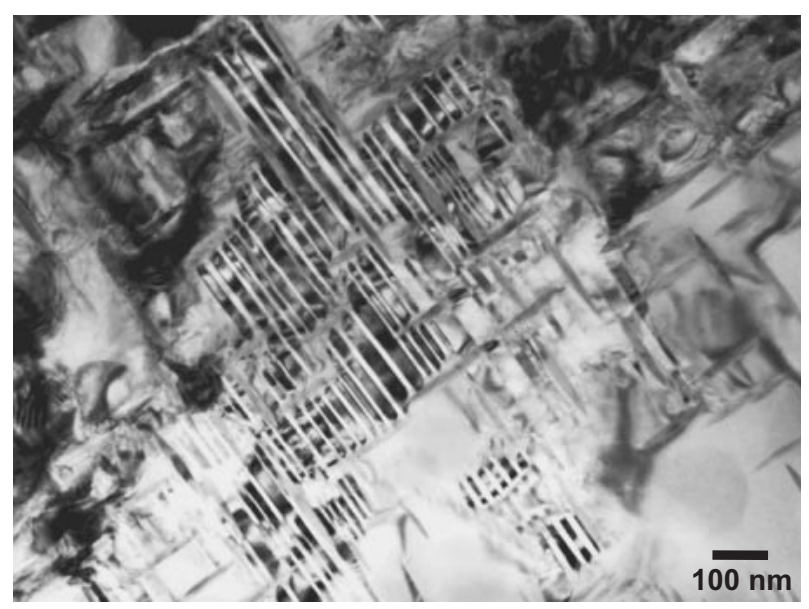

Fig. 8 Bright field image of Ti-6Zr-52Ni aged for $360 \mathrm{ks}$ at $773 \mathrm{~K}$.

itates is a super structure of the B2 phase. More detailed analysis of the precipitate structures is in progress.

Figure 7 shows a bright field (BF) image (a), [011 $]_{\mathrm{B} 2}$ SAD pattern (b) and its key diagram (c) for a sample aged in the same conditions as the one shown in Figure 6. Precipitates parallel to the trace of $(100)_{\mathrm{B} 2}$ can be seen, accompanied by coherency strain contrast. The SAD pattern exhibits the B2 main reflections which are indicated by black circles in the key diagram (Fig. 7(c)). Additional diffuse satellite spots are elongated parallel to $\langle 100\rangle_{\mathrm{B} 2}$ directions. They are situated at $1 / 3\langle 01 \overline{1}\rangle_{\mathrm{B} 2}$ positions and at $1 / 2\langle 111\rangle_{\mathrm{B} 2}$ between $\mathrm{B} 2$ main spots. The key diagram depicts them as dark gray ellipses. Fade streak-like reflections are also noted in Fig. 7(b). The key diagram indicates them as light gray segments. These reflections are found at $1 / 4\langle 11 \overline{1}\rangle_{\mathrm{B} 2}$ and they are oriented parallel to $\langle\overline{1} 1 \overline{1}\rangle_{\mathrm{B} 2}$. The second family of streak-like reflections aligned parallel to $\langle 11 \overline{1}\rangle_{\mathrm{B} 2}$ can be also seen.

Figure 8 depicts the $\mathrm{BF}$ image for the sample aged at $773 \mathrm{~K}$ for $360 \mathrm{ks}$. The precipitates grow to the much larger diameter of $160 \mathrm{~nm}$ and a thickness of $\sim 30 \mathrm{~nm}$. Martensite phase fills the space between the precipitates, suggesting that the coarse precipitates act as obstacles for the growth of martensite plates. Furthermore, one can note the absence of dark contrasts around the precipitates, indicating a diminished coherency strain.

A drastic increase in microhardness was noted in the sample aged at $673 \mathrm{~K}$ up to $144 \mathrm{ks}$ as shown in Fig. 9.

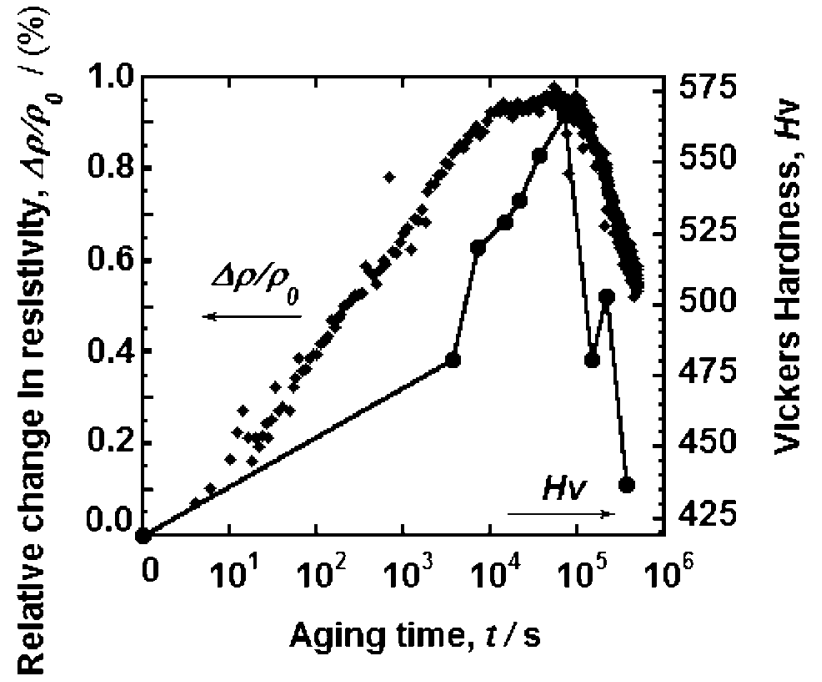

Fig. 9 Relative changes in electrical resistivity and microhardness as a function of aging time at $673 \mathrm{~K} ; \rho_{0}$ - electrical resistivity for the ashomogenized state; $\Delta \rho$ - the change of electrical resistivity with aging time.

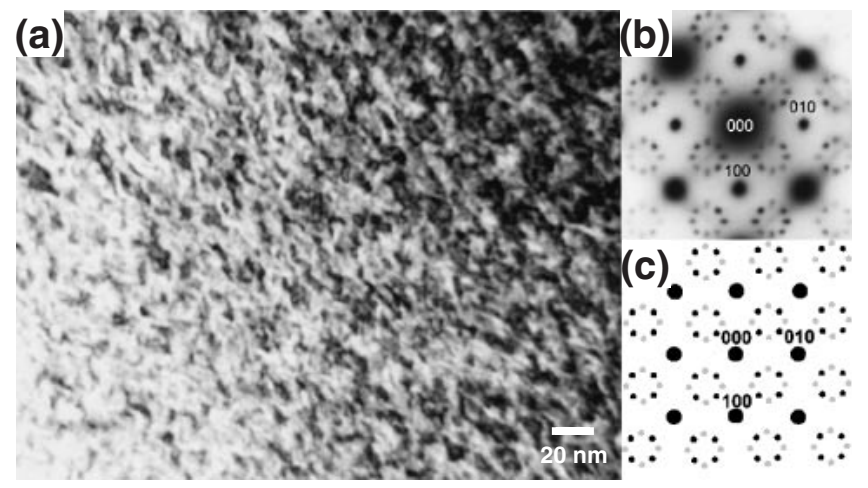

Fig. 10 Microstructure of Ti-6Zr-52Ni aged $360 \mathrm{ks}$ at $673 \mathrm{~K}$ : (a) Bright field image. (b) selected area diffraction pattern $\left(\mathrm{e}^{-} / /[001]_{\mathrm{B} 2}\right)$; (c) key diagram.

Concomitantly, a small but systematic variation in electrical resistivity was observed. In terms of microstructures, aging at $673 \mathrm{~K}$ for up to $144 \mathrm{ks}$ did not alter the structure and the features of electron diffraction patterns. Figure 10 shows the TEM image of the sample aged at $673 \mathrm{~K}$ for $360 \mathrm{ks}$. Conventional TEM observations shown in Fig. 10(a) does not clearly reveal the precipitates but satellites are seen at $1 / 3\langle 110\rangle_{\mathrm{B} 2}$ and $1 / 4\langle 210\rangle_{\mathrm{B} 2}$ positions in the SAD pattern shown in Fig. 10(b). These positions are the same as those of the satellites shown in Fig. 3(b) but their shapes are spotty. HRTEM image with the electron beam parallel to $[001]_{\mathrm{B} 2}$ is presented in Fig. 11(a). A precipitate is seen in the area delineated by a dotted circle of about $5 \mathrm{~nm}$. The insets D and E show the FFT images for the corresponding areas in Fig. 11(a). The FFT image D exhibits only B2 reflections with no additional spots while the inset $\mathrm{E}$ exhibits the satellite spots at $1 / 3\langle 110\rangle_{\mathrm{B} 2}$ positions. These reflections are denoted as small black solid circles in the key diagram (Fig. 11(b)). It is difficult to assess the precipitates shape in these cases but the satellite spots shown in Fig. 10(b) suggest that they are spherical as delineated by the dotted lines in the area $E$ in Fig. 11(a). 


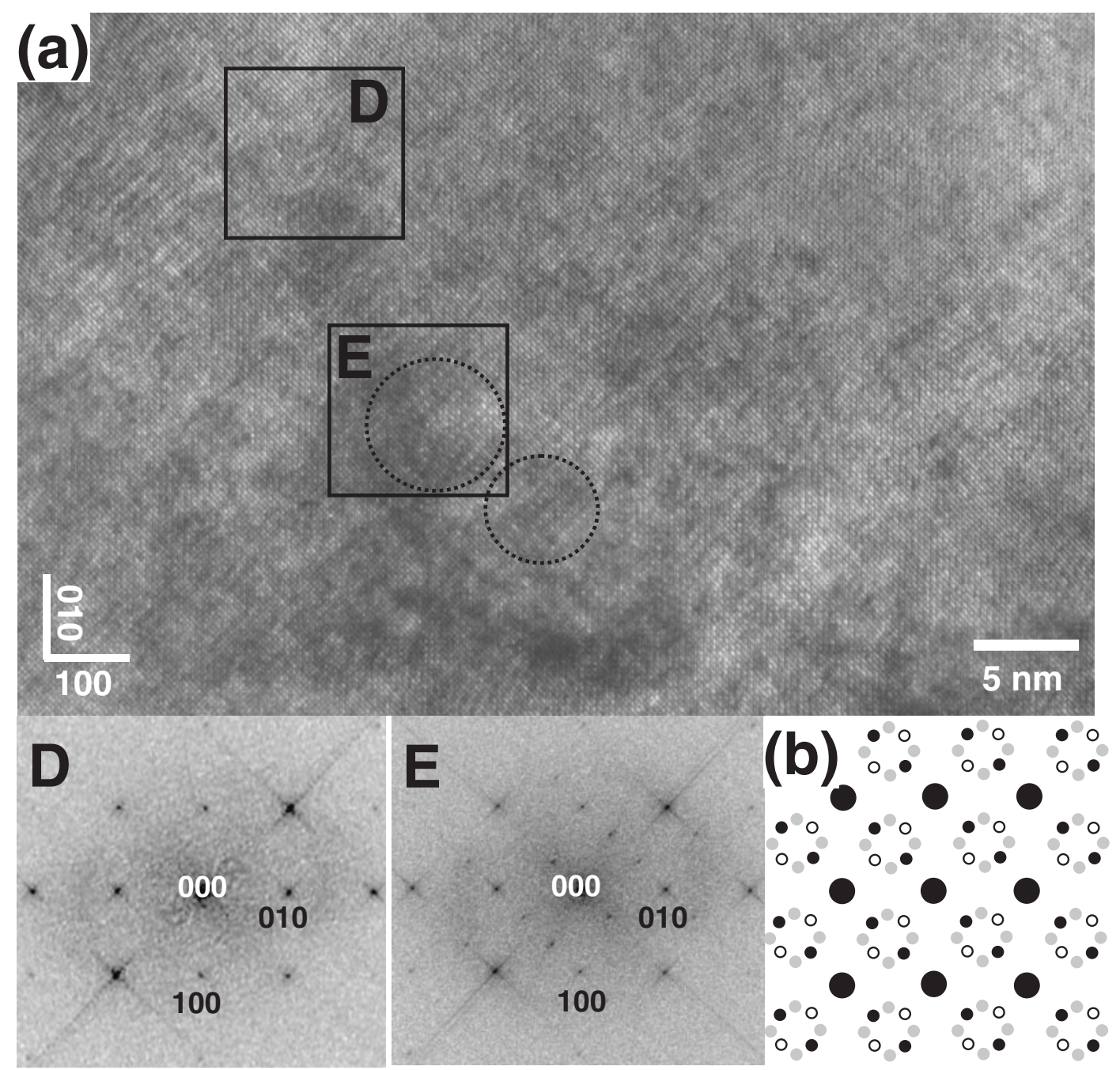

Fig. 11 Microstructure of Ti-6Zr-52Ni aged for $360 \mathrm{ks}$ at $673 \mathrm{~K}$ : (a) high resolution TEM image (e $\left.\mathrm{e}^{-} / /[001]_{\mathrm{B} 2}\right)$. Insets D and E are the fast Fourier transformation (FFT) images of area D and E in (a), respectively; (b) key diagram for FFT images.

Electrical resistivity is sensitive to a change in the density of lattice defects, e.g., dislocations and vacancies, second phases and also to a change in short range or long range ordered atomic arrangements. Electrical resistivity increased with aging time up to $72 \mathrm{ks}$ for aging at $673 \mathrm{~K}$, as shown in Fig. 9. This is closely followed by the microhardness increase. TEM investigations showed no precipitation process for this aging duration. The SAD pattern revealed only a change in the diffuse scattering intensity. Moreover, it was shown that after aging at $673 \mathrm{~K}$ for $72 \mathrm{ks}$ no transformation peaks were seen in DSC and the microhardness was the highest. ${ }^{10)}$ Thus, it may be inferred the previously described evolutions may be related to a change in the short range ordered structures. For longer aging both resistivity and hardness decreased and this was accompanied by the appearance of precipitates as shown for the samples aged for $360 \mathrm{ks}$ (Fig. 11).

\subsection{Effect of deformation on microstructures in aged Ti- $6.0 \mathrm{~mol} \% \mathrm{Zr}-53 \mathrm{~mol} \% \mathrm{Ni}$}

The microstructural changes during aging and their influence on mechanical behaviour were assessed for a Ti$6.0 \mathrm{~mol} \% \mathrm{Zr}-53 \mathrm{~mol} \% \mathrm{Ni}$ alloy. Cylindrical samples were compression tested for an imposed deformation of about
$8 \%$ for five consecutive cycles.

Figure 12 exhibits the BF micrograph for a sample aged $3.6 \mathrm{ks}$ at $773 \mathrm{~K}$. The SAD pattern shown as the inset of Fig. 12 reveals circular diffuse scattering similar to the ones observed in Fig. 1. The BF image also depicts a high density of dislocations introduced during the cyclic deformation. Since the sample exhibited only a small plastic strain, ${ }^{14)}$ it can be inferred that the most of the dislocations may be introduced during the forward/reverse transformation as a lattice invariant shear. This does not contradict with the aligned structure seen in Fig. 12, which is parallel to the $\{110\}_{\mathrm{B} 2}$ habit planes.

A low magnification BF image for the sample aged $144 \mathrm{ks}$ at $773 \mathrm{~K}$ is presented in Fig. 13(a). The image exhibits the B2 matrix containing uniformly distributed plate-like precipitates. The black arrows indicate the presence of residual martensite.

The precipitates are accompanied by coherency strain contrast as seen in Fig. 13(b). They have $\{100\}_{\mathrm{B} 2}$ habit. The SAD pattern indicates sharp satellite spots at $1 / 3\langle 110\rangle_{\mathrm{B} 2}$ and diffuse satellite at $1 / 4\langle 210\rangle_{\mathrm{B} 2}$ elongated in $\langle 100\rangle_{\mathrm{B} 2}$ directions. This SAD pattern is similar to the one presented in Fig. 3(b). There are few dislocations seen in this area, although some areas with a higher density of dislocations 


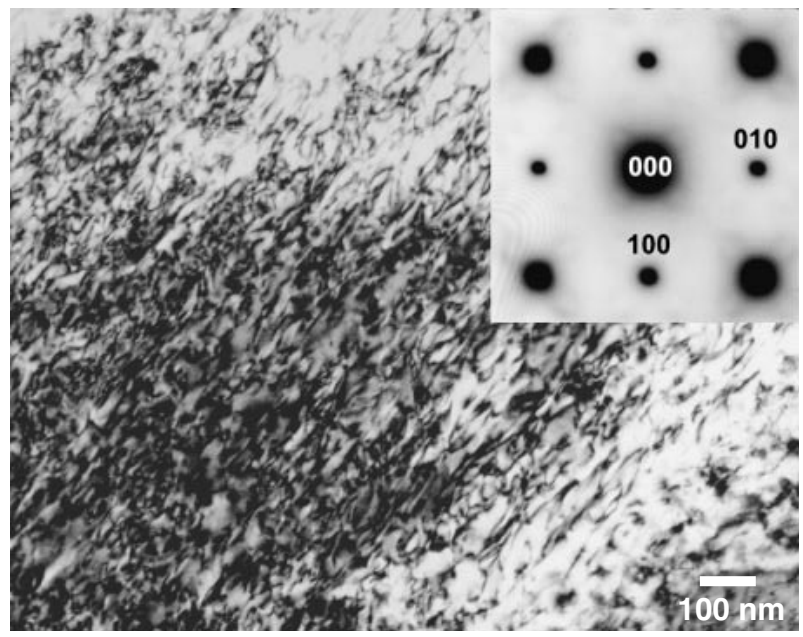

Fig. 12 Bright field image of Ti-6Zr-53Ni aged for $3.6 \mathrm{ks}$ at $773 \mathrm{~K}$ and compression tested for 5 cycles and corresponding electron diffraction pattern (inset, $\mathrm{e}^{-} / /[001]_{\mathrm{B} 2}$ ).
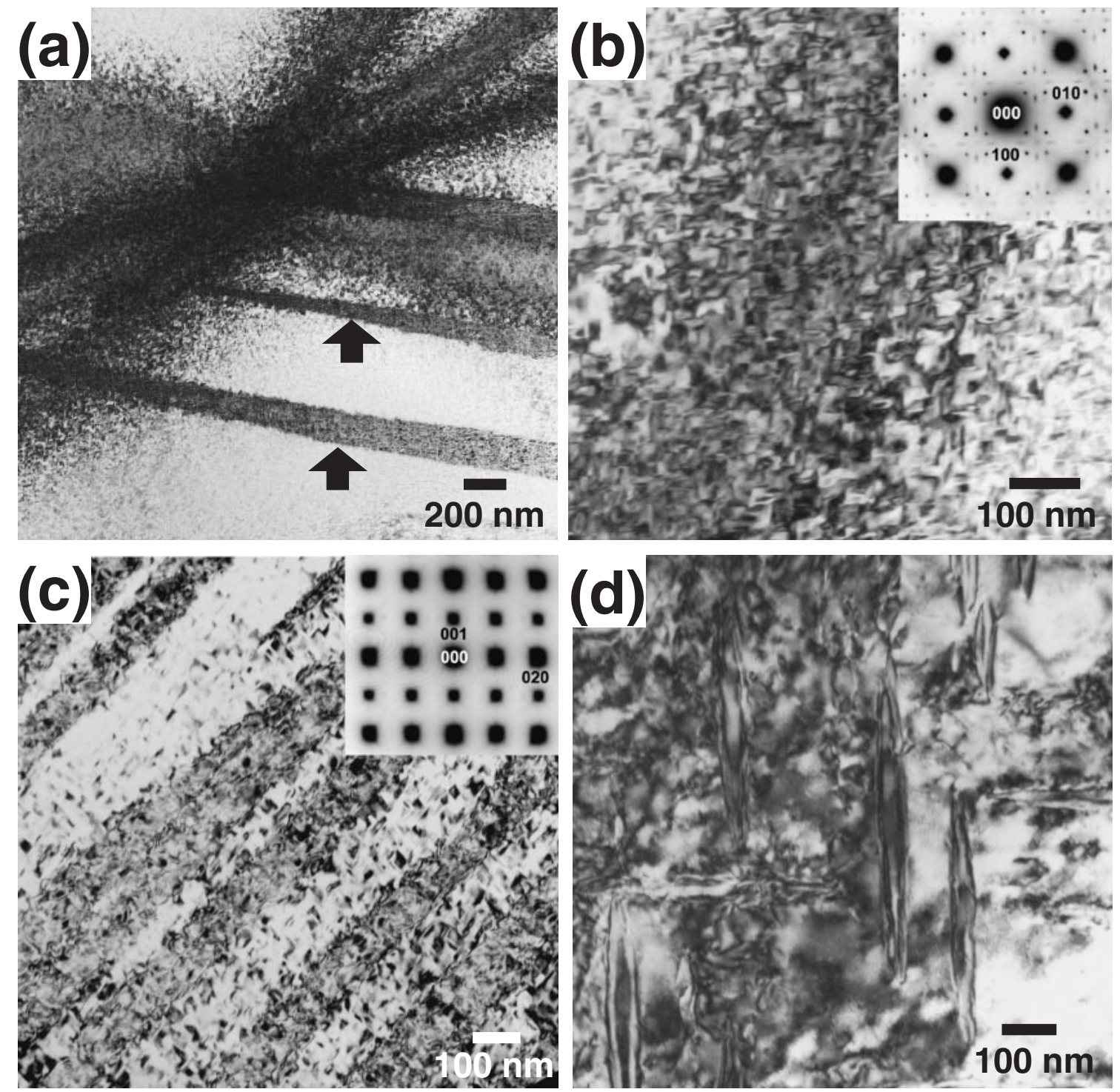

Fig. 13 TEM bright field image of Ti-6Zr-53Ni aged at $773 \mathrm{~K}$ : (a) $144 \mathrm{ks}$, (b) higher magnification image of BF presented in (a); (c) precipitates inside martensite phase and (d) $360 \mathrm{ks}$. 


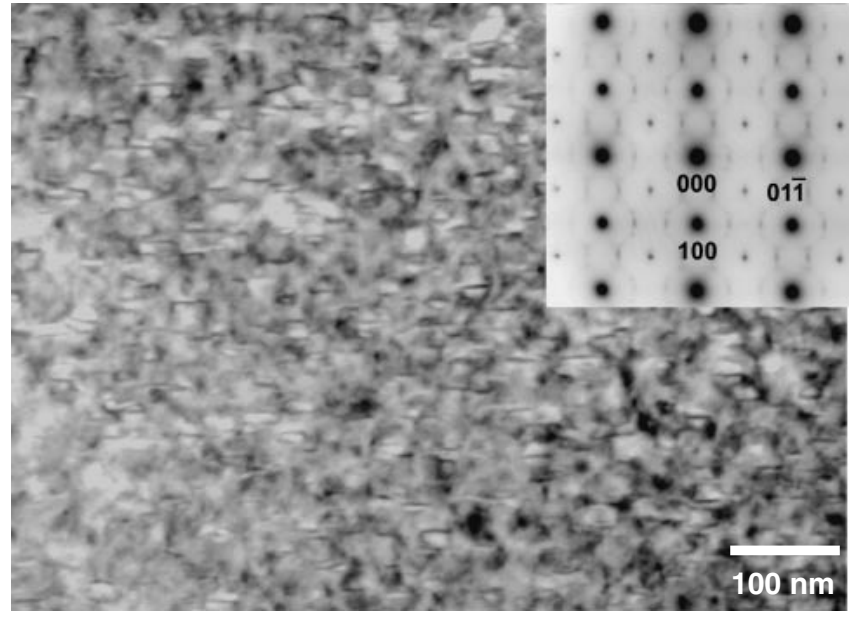

Fig. 14 Bright field image of Ti-11.1Zr-51.5Ni aged for $144 \mathrm{ks}$ at $723 \mathrm{~K}$ and corresponding electron diffraction pattern (inset, $\mathrm{e}^{-} / /[011]_{\mathrm{B} 2}$ ).

presented in the followings. Figure 14 exhibits the BF micrograph for a sample aged $144 \mathrm{ks}$ at $723 \mathrm{~K}$. The SAD pattern shown as the inset of Fig. 14 reveals additional satellite spots situated at $1 / 2\langle 11 \overline{1}\rangle_{\mathrm{B} 2}$. Diffuse elongated spots oriented parallel with $\langle 100\rangle_{\mathrm{B} 2}$ are also found. The BF image presents numerous precipitates uniformly distributed in B2 matrix. They have a diameter of around $30 \mathrm{~nm}$ and a thickness of $10 \mathrm{~nm}$. The coherency strain contrasts can be observed around the precipitates. This is an indication that same type of precipitates as presented in Fig. 3-12 can be obtained in higher $\mathrm{Zr}$ content alloy after aging as well.

However, the distribution of the precipitates is not uniform after aging at $773 \mathrm{~K}$ for $144 \mathrm{ks}$. As shown in Fig. 15, the precipitates tend to form colonies. Their dimensions vary from $50 \mathrm{~nm}$ to $100 \mathrm{~nm}$. Also, it seems that precipitation process may have an autocatalytic character as observed for the precipitation of $\mathrm{Ti}_{3} \mathrm{Ni}_{4}$ phase in binary TiNi alloys. ${ }^{15}$ ) New precipitates tend to nucleate and grow in the elastic strain field generated by another precipitate.

\section{Summary}

Effect of isothermal aging on microstructure in Ti$6.0 \mathrm{~mol} \% \mathrm{Zr}-52 \mathrm{~mol} \% \mathrm{Ni}$ and $\mathrm{Ti}-11.1 \mathrm{~mol} \% \mathrm{Zr}-51.5 \mathrm{~mol} \% \mathrm{Ni}$ alloy was investigated. The influence of aging on microstructure after cyclic compression deformation in $\mathrm{Ti}$ $6.0 \mathrm{~mol} \% \mathrm{Zr}-53 \mathrm{~mol} \% \mathrm{Ni}$ alloy was also assessed. These alloys exhibit two-stage aging behaviour. Namely, the first stage exhibits no microstructural changes during aging. This is associated with some intensification of the diffuse scattering in electron diffraction patterns and an increase in electrical resistivity, probably due to a short range ordering process. The second stage is clearly related to the fine coherent precipitation accompanied by a decrease in electrical resistivity. The precipitates in the samples aged at $773 \mathrm{~K}$ are lenticular with $\{100\}_{\mathrm{B} 2}$ habit. The electron

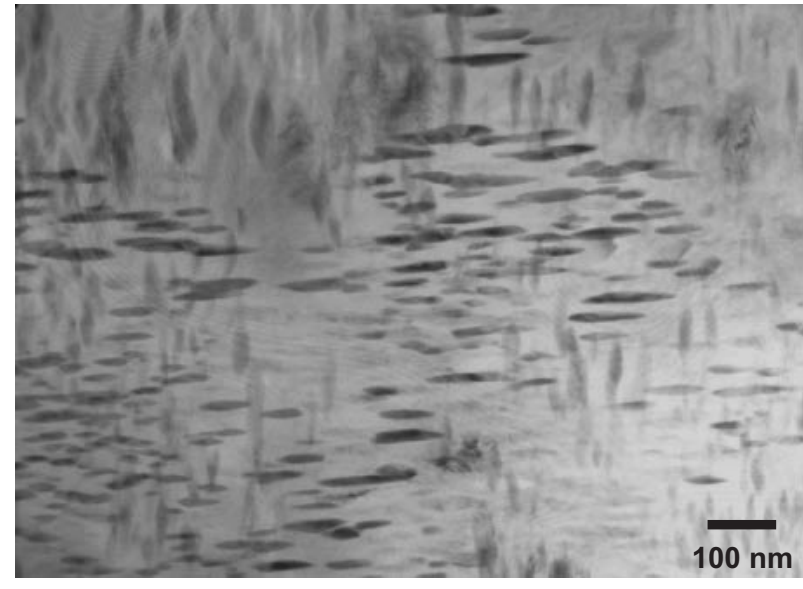

Fig. 15 Bright field image of Ti-11.1Zr-51.5Ni aged for $144 \mathrm{ks}$ at $773 \mathrm{~K}$.

diffraction patterns are characterized by $1 / 3\langle 110\rangle_{\mathrm{B} 2}$ satellite spots, indicating that the structure is a super structure of the B2 phase. This is consistent with the high resolution electron microscopy and FFT analysis. Aging at $673 \mathrm{~K}$ produced the spherical precipitates but they exhibit similar characteristic satellite reflections in electron diffraction. The more detailed study on the structure of the precipitates is currently under way.

The matrix containing fine precipitates shows low dislocation density after cyclic compression loading. Residual martensite plates containing numerous precipitates were occasionally found, which suggests that the coherent precipitates do not interfere with martensitic transformation.

\section{REFERENCES}

1) M. Nishida, C. M. Wayman and T. Honma: Metall. Trans. 17 (1986) 1505.

2) G. S. Fristov, J. van Hubeeck and Y. N. Koval: Scripta Mater. 50 (2004) 243.

3) J. Beyer and J. H. Mulder: MRS Symp. Proc. 360 (1995) 443.

4) L. Meisner and V. Sivokha: Journal de Physique C8 (1995) 765.

5) J. H. Mulder, J. H. Maas and J. Beyer: Proc. International Conference on Martensitic Transformation, (Monterey Institute of Advanced Studies, 1996) 869.

6) L. L. Meisner, V. P. Sivokha and O. B. Perevalova: Phisica B 262 (1999) 49

7) S.-H. Kang, H.-J. Im, H.-W. Lee and T.-H. Nam: Metals and Materials International 7 (1999) 201.

8) S. K. Wu and S. F. Hsieh: J. Alloys. Comp. 297 (2000) 294.

9) V. P. Sivokha and L. L. Meisner: Phisyca B 296 (2001) 329.

10) A. Sandu, K. Tsuchiya, S. Yamamoto, Y. Todaka and M. Umemoto: Mater. Science Forum 539-543 (2007) 3163.

11) Y. Murakami and D. Shindo: Phil. Mag. Lett. 81 (2001) 631.

12) T. Kikuchi, K. Ogawa, S. Kajiwara, T. Matsunaga, S. Miyazaki and Y. Tomota: Philos. Mag. 78A (1998) 467.

13) S. Kajiwara, T. Kikuchi, K. Ogawa, T. Matsunaga and S. Miyazaki: Philos. Mag. Lett. 74 (1996) 137.

14) A. M. Sandu, K. Tsuchiya, S. Yamamoto, Y. Todaka and M. Umemoto: Scripta Mater 55 (2006) 1079.

15) J. K. Allafi, A. Dlouhy and G. Eggeler: Acta Mater. 50 (2002) 4255. 